\title{
THE SALIVARY CONCENTRATION OF STREPTOCOCCI MUTANS AND STREPTOCOCCI SANGUIS AND THEIR COLONIZATION OF ARTIFICIAL TOOTH FISSURES IN MAN
}

\author{
Mona Svanberg* and W. J. Loesche \\ Department of Oral Biology and The Dental Research Institute, \\ The University of Michigan, School of Dentistry, Ann Arbor, \\ Michigan 48104, U.S.A.
}

\begin{abstract}
Summary-Artificial fissures were inserted in 3 subjects for $1-21$ days. At a salivary concentration of $10^{3}$ colony-forming units (CFU) Strep. mutans $/ \mathrm{ml}$, fissures were colonized by this organism. The proportional distribution of Strep. mutans increased with time and comprised up to 6 per cent of the total number of organisms in the fissure at day 21 . The total number of organisms in the fissure did not increase with time after 1 day. The salivary concentration of Strep. sanguis was about $10^{6} \mathrm{CFU} / \mathrm{ml}$ in all subjects. The proportional distribution of this organism in the fissure varied both between different individuals and with time in the same individual. When the artificial fissures were inserted during a regimen which reduced the salivary concentrations of Strep. mutans, the organism did not colonize the artificial fissures, even though the salivary concentration of Strep. mutans after cessation of the regimen increased to levels generally associated with colonization. If the fissures had been inserted 2 weeks before the Strep. mutans reducing regimen was started, the reduction of the number of Strep. mutans in the saliva to levels generally not associated with colonization did not influence the proportional distribution of Strep. mutans in the artificial fissure. These observations indicate that the initial inoculum is a main determinant for the colonization of the artificial fissures by Strep. mutans.
\end{abstract}

\section{INTRODUCTION}

Strep. mutans is significantly increased in fissure plaque associated with dental decay (Ikeda, Sandham, and Bradley, 1973; Loesche et al., 1975). The microbial flora of fissures is difficult to assess completely because of the inability of sampling devices to penetrate the narrow orifice of the fissure. Fissure models have been devised which permit the quantitative recovery of bacteria from a fissure (Theilade, Larson and Karring, 1973). These models consist of Mylar fissures placed in gold inlays (Loe, Karring and Theilade, 1973) or natural fissures of unerupted third molars (Folke, Sveen and Thott. 1973; Theilade et al., 1974) secured by various means. A Gram-positive coccal flora dominated in both model fissures (Theilade et al., 1973, 1974; Thott, Folke and Sveen, 1974). Strep. sanguis was uniformly isolated and appeared to be the predominant organism. Strep. mutans was infrequently found in fissures placed in Danish subjects (Theilade et al., 1973, 1974) but was found in all subjects and in most fissures of American subjects (Thott et al., 1974) The salivary levels of Strep. mutans and Strep. sanguis appear to be important determinants in the colonization of smooth surfaces (van Houte and Green, 1974).

\section{MATERIAL AND METHODS}

Three adult subjects participated. The decayed, missing, filled surfaces (DMFS) scores were 38 in male

\footnotetext{
* Present address: Odontologiska Kliniken, Götesborg
} Universitet. Fack, 40033 Göteborg 33. Sweden. subject $G, 52$ in male subject $T$ and 78 in female $S$. The subjects had no missing teeth and no active carious lesions. Subjects $G$ and $T$ brushed and flossed their teeth daily, whereas $S$ brushed but did not floss and used toothpicks occasionally. Subject $S$ ate sweets between meals, whereas $T$ and $G$ did not.

The three subjects had an occlusal surface on a molar tooth prepared to receive a gold inlay containing a Mylar bag with the shape and dimensions of a natural fissure. This Mylar fissure and gold inlay, hereafter referred to as an artificial fissure, were autoclaved and secured with gutta percha in a maxillary first molar in $G$, and in mandibular first molars in $T$ and $S$. The artificial fissures were always inserted in the mornings. After removal from the mouth, the Mylar bags were separated from the gold inlay using sterile instruments.

Unstimulated saliva was collected twice daily, morning and afternoon in the 1,2 and 5 day experiments. In the longer experiments, saliva was sampled once daily, in the morning, with the exception of weekends when no samples were collected. Saliva was sampled immediately before the insertion and removal of the artificial fissures. One $\mathrm{ml}$ of saliva was added to $9 \mathrm{ml}$ of reduced transport fluid (RTF)(Syed and Loesche, 1972). The inlay containing the artificial fissure was removed at various time intervals and the content of the artificial fissure placed into $10 \mathrm{ml}$ of RTF. The samples were dispersed by sonification for $5 \mathrm{~s}$ (Branson W 185 D. N.Y.), serially diluted in RTF, and plated in duplicate over a 3 log dilution range on mitis-salivarius-bacitracin agar (MSB) (Gold, Jor- 
dan and van Houte, 1973) and MM10 sucrose agar (Loesche and Syed, 1973). The plates were incubated at $37^{\circ} \mathrm{C}$ in 85 per cent $\mathrm{N}_{2}, 10$ per cent $\mathrm{H}_{2}$ and 5 per cent $\mathrm{CO}_{2}$ for $48 \mathrm{~h}$. All samples were processed and placed in the anaerobic chamber (Coy Manufacturing Co., Ann Arbor, Mich.) less than $30 \mathrm{~min}$ after collection. Strep. mutans was identified by colonial morphology on MSB agar and by mannitol fermentation of representative isolates. Strep. sanguis was identified as an adherent raised colony on MM10 sucrose agar (Loesche and Syed, 1973). The total colony-forming units count was obtained from MM10 sucrose agar plates.

Subjects $T$ and $S$ had relatively high levels of Strep. mutans in their saliva and the artificial fissures placed in their mouths were readily colonized by Strep. mutans. Experiments were performed to lower their salivary Strep. mutans levels to observe what effect this would have on Strep. mutans colonization of the artificial fissures. A mouthwash solution containing $5 \mathrm{ml}$ of 0.4 per cent stannous fluoride and $5 \mathrm{ml}$ of 0.02 per cent acidulated phosphate fluoride (Iradicav $^{\circledR}$, Janar Co., Grand Rapids, Mi.) was used daily after brushing and flossing the teeth in the evening. Ingestion of sucrose between meals was avoided. This regimen was performed for 14 days prior to the insertion of the artificial fissures. Additional experiments were performed with subject $S$. In two experiments, the artificial fissures were inserted while subject $S$ was on the Strep. mutans reducing regimen and in two experiments the artificial fissures were in situ for 14 days prior to the introduction of the Strep. mutans reducing regimen.

\section{RESULTS}

The artificial fissures contained, after one day, a large number of microorganisms (Table 1). The total number did not change appreciably with time but the proportional distribution of Strep. mutans and Strep. sanguis varied considerably. Strep. mutans colonized the artificial fissures in two of the test subjects on each occasion, but in subject $G$ this organism was only detected on two occasions i.e. 9 and 12 days after insertion of the fissures.

Strep. sanguis colonized the artificial fissures in all
3 persons on all occasions. There was, however, considerable inter- and intra-individual variation with time of the proportional distribution of this organism. For example, in subject $G$, Strep. sanguis accounted for about 4-6 per cent of the total CFU on days 1 and 2 and increased to 21 per cent on days 12 and 21. In subject $S$, on the other hand, Strep. sanguis was prominent on days 1 and 2 but decreased with time. In this subject, Strep. mutans was present in low proportions i.e. $<1$ per cent on days 1 to 7 but increased to 6 per cent of the cultivable flora by day 21. Subject $T$ showed about the same pattern as subject $S$ with regard to Strep. mutans, but in $T$ Strep. sanguis accounted for 10-21 per cent of the total CFU at all times.

The salivary concentrations of Strep. sanguis were about $10^{6} \mathrm{CFU} / \mathrm{ml}$ in all subjects (Table 2), but the concentration of Strep. mutans varied considerably. In $G$ in whom the artificial fissures were colonized by Strep. mutans on two occasions, this organism constituted a minor part of the cultivable flora i.e. $0.01-0.02$ per cent, and the average salivary number was about $10^{2} / \mathrm{ml}$ (Table 3). Subjects $T$ and $S$ had an average value of about $10^{4}$ and $10^{6}$ CFU Strep. mutans per $\mathrm{ml}$ saliva respectively, and their artificial fissures were -olonized by Strep. mutans on all occasions. These data suggest that colonization of the artificial fissures by Strep. mutans takes place within one day, provided that the salivary concentration of this organism is above a certain level.

To test this hypothesis, the artificial fissures were re-inserted multiple times into the 3 subjects and left in place for 1, 2 or 5 days (Table 4). In $G$ on 15 separate occasions, the artificial fissures were not colonized by Strep. mutans, but in $T$ and $S$ they were readily colonized by this organism at all trials. Subject $G$ had an average of $2.5 \times 10^{2} \mathrm{CFU} /$ Strep. mutans per $\mathrm{ml}$ saliva and only 7 out of 95 separate cultures showed a count $>10^{3} \mathrm{CFU} / \mathrm{ml}$. The average salivary Strep. mutans in $T$ was $1.0 \times 10^{4}$ and in $S$ was $0.4 \times 10^{6} \mathrm{CFU} / \mathrm{ml}$ (Table 4). The lowest average salivary Strep. mutans count in $T$ in which the artificial fissures became colonized by this organism was $1.0 \times 10^{3} \mathrm{CFU} / \mathrm{ml}$, whereas, in subject $S$, this low value was about $3.2 \times 10^{4} \mathrm{CFU} / \mathrm{ml}$.

A Strep. mutans reducing regimen (SMRR), consisting of a combination of daily brushing and flossing

Table 1. Strep. mutans and Strep. sanguis as percentage of total colony-forming units (CFU) in the artificial fissure (AF) after $1,2,5,7,9 ; 12$ and 21 days colonization in subjects $G, T$ and $S$

\begin{tabular}{|c|c|c|c|c|c|c|c|c|c|}
\hline $\begin{array}{l}\text { Subject } \\
\text { Time }\end{array}$ & $\begin{array}{c}\text { Strep. } \\
\text { mutans } \\
\%\end{array}$ & $\begin{array}{c}G \\
\text { Strep. } \\
\text { sanguis } \\
\%\end{array}$ & $\begin{array}{l}\text { Total } \\
\text { CFU* }\end{array}$ & $\begin{array}{c}\text { Strep. } \\
\text { mutans } \\
\%\end{array}$ & $\underset{\substack{\text { Strep. } \\
\text { sanguis }}}{T}$ & $\begin{array}{l}\text { Total } \\
\text { CFU }\end{array}$ & $\begin{array}{c}\text { Strep. } \\
\text { mutans } \\
\%\end{array}$ & $\begin{array}{c}S \\
\text { Strep. } \\
\text { sanguis } \\
\%\end{array}$ & $\begin{array}{l}\text { Total } \\
\text { CFU }\end{array}$ \\
\hline 1 day & 0 & 5.6 & $4.5 \times 10^{7}$ & 0.03 & 10.5 & $0.7 \times 10^{7}$ & 0.02 & 17.6 & $0.5 \times 10^{7}$ \\
\hline 2 & 0 & 3.9 & 9.7 & 0.1 & 15.2 & 0.4 & 0.1 & 24.0 & 0.8 \\
\hline 5 & 0 & 10.9 & 3.5 & 0.03 & 12.2 & 3.3 & 0.02 & 4.2 & 5.3 \\
\hline 7 & 0 & 18.5 & 3.4 & 0.02 & 19.5 & 5.1 & 0.9 & 6.3 & 2.0 \\
\hline 9 & 0.02 & 15.6 & 4.8 & 1.1 & 14.2 & 2.5 & 1.4 & 5.3 & 1.3 \\
\hline 12 & 0.01 & 20.8 & 1.5 & 1.3 & 20.8 & 2.1 & 3.8 & 4.6 & 0.8 \\
\hline 21 & 0 & 26.9 & 1.1 & 4.4 & 19.2 & 0.9 & 6.3 & 1.1 & 1.2 \\
\hline
\end{tabular}

\footnotetext{
* Total viable count on MM10 sucrose agar incubated anaerobically for $48 \mathrm{~h}$.
} 
Table 2. Concentration of Strep. sanguis in saliva during periods of colonization of the artificial fissures in subjects $G, T$ and $S$

\begin{tabular}{|c|c|c|c|c|c|c|}
\hline \multirow{2}{*}{$\begin{array}{c}\text { Subject } \\
\text { Time }\end{array}$} & \multicolumn{2}{|c|}{$G$} & \multicolumn{2}{|c|}{$T$} & \multicolumn{2}{|c|}{$S$} \\
\hline & & $\overline{\mathrm{x}}^{*}$ range & & $\bar{x}^{*}$ range & & $\overline{\mathrm{x}}^{*}$ range \\
\hline 1 day & $n^{\dagger}=3$ & $0.5(0.3-0.8)$ & $n=3$ & $5.0(3.0-8.0)$ & $n=3$ & $1.6(1.3-2.0)$ \\
\hline 2 & $n=5$ & $2.5(0.4-6.4)$ & $n=5$ & $0.6(0.5-1.0)$ & $n=5$ & $2.5(1.0-4.0)$ \\
\hline 5 & $n=11$ & $2.0(0.4-4.0)$ & $n=11$ & $3.0(0.1-6.4)$ & $n=11$ & $5.1(0.2-10.0)$ \\
\hline 7 & $n=5$ & $0.6(0.6-0.6)$ & $n=5$ & $1.6(0.8-3.0)$ & $n=7$ & $2.0(1.3-6.4)$ \\
\hline 9 & $n=8$ & $0.8(0.5-1.3)$ & $n=8$ & $1.3(0.8-6.4)$ & $n=8$ & $1.6(1.0-6.4)$ \\
\hline 12 & $n=10$ & $1.6(0.4-4.0)$ & $n=5$ & $0.5(0.3-5.1)$ & $n=11$ & $1.3(0.5-4.0)$ \\
\hline & $n=15$ & $1.3(0.4-4.0)$ & $n=11$ & $0.6(0.3-13.1)$ & $n=16$ & $1.6(0.6-6.4)$ \\
\hline Average & $n=57$ & $1.3(0.3-4.0)$ & $n=48$ & $1.3(0.1-13.1)$ & $n=61$ & $2.0(0.2-10.0)$ \\
\hline
\end{tabular}

$\overline{\mathrm{x}}^{*}=$ mean number of Strep. sanguis per $\mathrm{ml}$ of saliva $\times 10^{6}$.

$n \dagger=$ number saliva samples collected at each time trial.

of the teeth, daily fluoride rinses and between-meal sucrose restriction was administered for two weeks prior to a series of experiments in which the artificial fissure was re-inserted multiple times in subjects $T$ and $S$. This SMRR lowered the salivary levels of Strep. mutans to an average of $0.8 \times 10^{3} \mathrm{CFU} / \mathrm{ml}$ in subject $T$ during the several weeks in which the experiments were performed (Table 5). Only 4 out of 10 artificial fissures inserted in $T$ became colonized by Strep. mutans. When colonization of the fissures occurred, the average salivary Strep. mutans level ranged from 0.3 to $4.0 \times 10^{3} \mathrm{CFU} / \mathrm{ml}$. The artificial fissures did not become colonized by Strep. mutans on 6 occasions when similar levels of this organism were present in the saliva. The detection of Strep. mutans in the artificial fissure in subject $T$ appeared to be a function of time, as no artificial fissures were colonized by Strep. mutans after 1 day in vivo, 2 of 4 were colonized by Strep. mutans after 2 days, and 2 of 3 were colonized by Strep. mutans after 5 days (Table 5). In $S$, the reduction of salivary Strep. mutans levels did not prevent colonization of the artificial fissure by this organism at any time period.

The experimental protocol was changed and the artificial fissure was inserted during a Strep. mutans reducing regimen in subject $S$. In one experiment (Fig. 1a), the artificial fissure was inserted at zero time and removed after 14 days. The Strep. mutans reducing regimen was administered for the first 7 days, during which time the salivary levels of Strep. mutans ranged from 1.6 to $6.5 \times 10^{3} \mathrm{CFU} / \mathrm{ml}$. After cessation of the

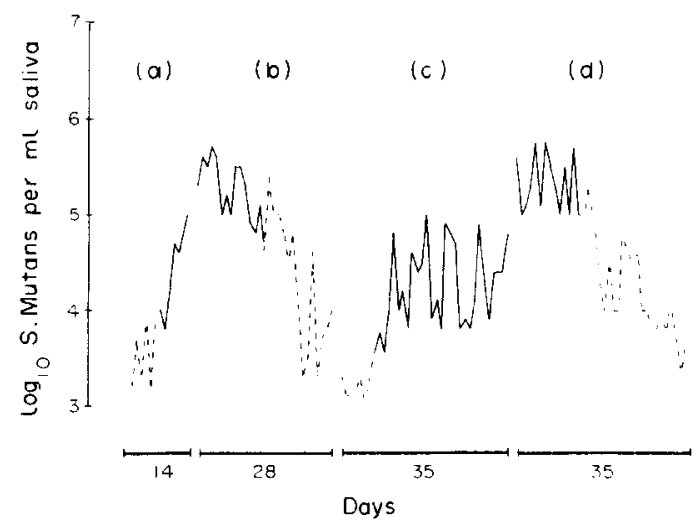

Fig. 1. Variations in salivary Strep. mutans concentration in subject $S$ during different experimental conditions of the SMRR. .-...- during the SMRR; - in the absence of the SMRR. The four experiments are designated as a, $b, c$, and $d$.

Table 3. Concentration of Strep. mutans in saliva during periods of colonization of the artificial fissures (AFs) in subjects $G, T$ and $S$

\begin{tabular}{llccccc}
\hline $\begin{array}{c}\text { Subject } \\
\text { Time }\end{array}$ & \multicolumn{2}{c}{$\begin{array}{c}G \\
\text { counts } \times 10^{2} \\
\overline{\mathrm{x}}^{*} \text { range }\end{array}$} & \multicolumn{2}{c}{$\begin{array}{c}T \\
\text { counts } \times 10^{4} \\
\overline{\mathbf{x}}^{*} \text { range }\end{array}$} & $\begin{array}{c}S \\
\text { counts } \times 10^{6} \\
\overline{\mathrm{x}}^{*} \text { range }\end{array}$ \\
\hline 1 day & $n \neq=3$ & $0.5(\mathrm{ND}+-1.5)$ & $n=3$ & $0.8(0.2-2.0)$ & $n=3$ & $0.4(0.2-0.6)$ \\
2 & $n=5$ & $2.0(\mathrm{ND}-7.0)$ & $n=5$ & $0.6(0.3-1.6)$ & $n=5$ & $1.0(0.2-1.6)$ \\
5 & $n=11$ & $0.2(\mathrm{ND}-2.0)$ & $n=11$ & $3.2(0.5-13.0)$ & $n=11$ & $1.0(0.1-3.2)$ \\
7 & $n=5$ & $20.0(7.0-70.0)$ & $n=5$ & $3.2(1.0-8.0)$ & $n=7$ & $1.2(0.3-4.0)$ \\
9 & $n=8$ & $26.0(10.0-70.0)$ & $n=8$ & $1.6(0.1-6.4)$ & $n=8$ & $0.6(0.2-1.2)$ \\
12 & $n=10$ & $26.0(1.0-40.0)$ & $n=5$ & $2.0(0.5-6.4)$ & $n=11$ & $1.2(0.6-8.0)$ \\
21 & $n=15$ & $1.6(\mathrm{ND}-10.0)$ & $n=11$ & $0.8(0.1-1.6)$ & $n=16$ & $1.0(0.1-5.0)$ \\
Average & $n=57$ & $2.5(\mathrm{ND}-70.0)$ & $n=48$ & $1.6(0.1-13.0)$ & $n=61$ & $1.0(0.1-8.0)$ \\
\hline
\end{tabular}

$\overline{\mathrm{X}}^{*}=$ mean number of Strep. mutans per ml saliva.

$\mathrm{ND}+=$ not detectable.

$n \ddagger=$ number saliva samples collected during each time trial. 
Table 4. Concentrations of Strep. mutans in saliva during 1, 2 and 5 days of colonization of the artificial fissures (AFs) in subjects $G, T$ and $S$

\begin{tabular}{lcccccc}
\hline Subject & No. & \multicolumn{1}{c}{$\begin{array}{c}G \\
\text { Time }\end{array}$} & $\begin{array}{c}\text { Strep. mutans } \times 10^{2} \\
\text { per ml saliva } \\
\bar{x}+\text { range }\end{array}$ & $\begin{array}{c}\text { Strep. mutans } \\
\text { in AF }\end{array}$ & $\begin{array}{c}\text { No. } \\
\text { experiments }\end{array}$ & $\mathrm{n}$ \\
\hline 1 day & 5 & 15 & $1.7($ ND-13.0) & ND & 4 & 12 \\
2 days & 5 & 25 & $3.0($ ND-21.0) & ND & 4 & 20 \\
5 days & 5 & 55 & 2.9 (ND-21.0) & ND & 4 & 44 \\
Average & 15 & 95 & $2.5($ ND-21.0) & $0 / 15$ & 12 & 76 \\
\hline
\end{tabular}

$n^{*}=$ number of saliva samples collected during each time trial.

$\bar{x} \dagger=$ mean number of Strep. mutans per ml saliva.

$\mathrm{ND} \ddagger=$ not detectable.

Strep. mutans reducing regimen, the salivary levels of Strep. mutans increased within the first few days to about $10^{5} \mathrm{CFU} / \mathrm{ml}$. When removed after 14 days, the artificial fissure contained the expected total number of microorganisms, including a large proportion of Strep. sanguis, but no detectable Strep. mutans (Table 6).

The artificial fissure was re-inserted and left in vivo for 28 days. The salivary Strep. mutans levels ranged from about $0.9 \times 10^{5}$ to $5 \times 10^{5} \mathrm{CFU} / \mathrm{ml}$ during the first 14 days (Fig. 1b). The Strep. mutans reducing regimen was initiated on day 15 and continued to day 28 . The salivary Strep. mutans levels decreased by day 21 to about $2 \times 10^{3}$ organisms per $\mathrm{ml}$. The artificial fissures were removed at day 28 and contained about 10 per cent Strep. mutans and 14 per cent Strep. sanguis (Table 6).

Both experimental variations of the Strep. mutans reducing regimen were repeated. The fissure was re-inserted while subject $S$ was on the Strep. mutans reducing regimen (Fig. 1c). The regimen was continued for 1 week during which the salivary levels of Strep. mutans were about $10^{3}$ organisms per $\mathrm{ml}$. The regimen was stopped at day 8 and the artificial fissure was left in vivo until day 35. The levels of Strep. mutans increased immediately and ranged from $5 \times 10^{3}$ to about $1 \times 10^{5}$ organisins per ml of saliva during this 28 day period. When the artificial fissures was cultured at day 35 , no Strep. mutans were detectable even though about $1 \times 10^{7} \mathrm{CFU}$ were present in the fissure (Table 6).

The fissure was next inserted while subject $S$ was off the Strep. mutans reducing regimen and had salivary Strep. mutans levels of about $1 \times 10^{5}$ to $5 \times 10^{5}$ organisms per $\mathrm{ml}$ of saliva (Fig. 1d). The artificial fissure was exposed to these salivary levels for 2 weeks, after which the Strep. mutans reducing regimen was initiated at day 15 and continued until day 35 . The salivary Strep. mutans levels declined about 50 fold during this 21 -day period, but the artificial fissure levels of Strep. mutans appeared to be unaffected (Table 6). This could be demonstrated by plotting the percentage of Strep. mutans in the artificial fissure against the number of days in which the fissure was present in vivo in subject $S$. The percentages of Strep. mutans in the artificial fissure at 9, 12 and 21 days in the absence of the SMRR (data taken from Table 1) and at 28 and 35 days in the presence of the SMRR

Table 5. Salivary concentrations of Strep. mutans during periods of colonization of the artificial fissures after 2 weeks of a Strep. mutans reducing regimen in subjects $T$ and $S$

\begin{tabular}{|c|c|c|c|c|c|c|}
\hline \multirow{2}{*}{$\begin{array}{l}\text { Subject } \\
\text { Time }\end{array}$} & \multicolumn{3}{|c|}{$T$} & \multicolumn{3}{|c|}{$S$} \\
\hline & \multicolumn{2}{|c|}{ 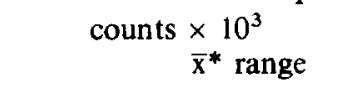 } & $\begin{array}{l}\text { Strep. mutans } \\
\text { in AF }\end{array}$ & \multicolumn{2}{|c|}{$\begin{aligned} \text { counts } & \times 10^{4} \\
& \bar{x}^{*} \text { range }\end{aligned}$} & $\begin{array}{l}\text { Strep. mutans } \\
\text { in AF }\end{array}$ \\
\hline 1 day & $n \ddagger=3$ & $0.4(0.2-0.6)$ & ND + & $n=3$ & $2.6(1.0-2.8)$ & + \\
\hline 1 & $n=3$ & $0.1(0.1-0.1)$ & ND & $n=3$ & $2.8(1.6-4.0)$ & + \\
\hline 1 & $n=3$ & $0.3(0.2-0.3)$ & ND & & & \\
\hline 2 days & $n=5$ & $0.6(0.1-1.3)$ & ND & $n=5$ & $4.0(1.0-13.0)$ & + \\
\hline & $n=5$ & $0.6(0.1-1.6)$ & + & $=5$ & $4.0(0.6-8.0)$ & + \\
\hline 2 & $n=5$ & $4.0(1.0-10.0)$ & ND & & & \\
\hline 2 & $n=5$ & $0.3(0.2-0.6)$ & + & & & \\
\hline 5 days & $n=11$ & $1.0(0.1-4.0)$ & ND & $n=11$ & $4.0(1.0-13.0)$ & + \\
\hline & $n=11$ & $3.0(0.6-6.0)$ & + & $n=11$ & $5.0(0.2-13.0)$ & + \\
\hline 5 & $n=11$ & $4.0(0.8-13.0)$ & + & & & \\
\hline Average & $n=62$ & $0.8(0.1-13.0)$ & $4 / 10+$ & $n=38$ & $3.2(0.2-13.0)$ & $6 / 6+$ \\
\hline
\end{tabular}

* $\overline{\mathrm{x}}=$ mean number of Strep. mutans per ml saliva.

$+\mathrm{ND}=$ not detectable.

$\ddagger n=$ number saliva samples collected during each time trial. 
Table 4. Continued

\begin{tabular}{cccccc}
$\begin{array}{c}\text { Strep. mutans } \times 10^{4} \\
\text { per ml saliva } \\
\overline{\mathbf{x}}+\text { range }\end{array}$ & $\begin{array}{c}\text { Strep. mutans } \\
\text { in AF }\end{array}$ & $\begin{array}{c}\text { No. } \\
\text { experiments }\end{array}$ & n & $\begin{array}{c}\text { Strep. mutans } \times 10^{6} \\
\text { per ml saliva } \\
\overline{\mathbf{x}}+\text { range }\end{array}$ & $\begin{array}{c}\text { Strep. mutans } \\
\text { in AF }\end{array}$ \\
\hline $0.8(0.02-5.1)$ & + & 3 & 9 & $0.2(0.006-0.9)$ & + \\
$1.1(0.01-10.0)$ & + & 3 & 15 & $0.4(0.004-1.6)$ & + \\
$1.0(0.01-12.0)$ & + & 3 & 33 & $0.4(0.01-3.2)$ & + \\
$1.0(0.01-12.0)$ & $12 / 12 \$$ & 9 & 57 & $0.4(0.004-3.2)$ & $9 / 9 s$ \\
\hline
\end{tabular}

$\$$ number of times Strep. mutans was detected in AF divided by total number of experiments.

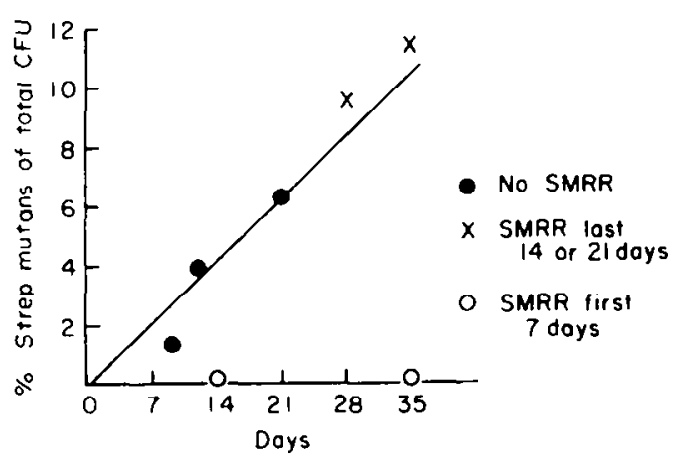

Fig. 2. The proportions of Strep. mutans in the artificial fissure in subject $S$ during different time periods and experimental conditions.

fell on the same line (Fig. 2). The two points obtained when the artificial fissure was inserted at the same time that the SMRR began are not on this line.

\section{DISCUSSION}

The artificial fissures were colonized within 1 day by a large number of microorganisms. The total number did not change appreciably in the fissures left in situ for 2-3 weeks, indicating that the majority of space is quickly filled with bacteria and that the microorganisms remain viable in the fissure for a long period.

The microorganisms must have been introduced in the artificial fissure via the saliva or translocated via contact from adjacent tooth surfaces as suggested by Löe et al. (1973). We found that the salivary levels of Strep. sanguis and Strep. mutans could be associ- ated with their presence in artificial fissures. Strep. sanguis averaged about $10^{\circ} \mathrm{CFU} / \mathrm{ml}$ of saliva. This organism colonized the fissures in the 3 subjects on all occasions and comprised from 6 to 18 per cent of the cultivable flora after 1 day. Strep. mutans colonized the artificial fissures on all occasions in the two subjects in whom the salivary counts of Strep. mutans were about $10^{4} \mathrm{CFU} / \mathrm{ml}$ or higher. In the third subject, in whom the salivary number of Strep. mutans usually averaged about $10^{2} \mathrm{CFU} / \mathrm{ml}$, Strep. mutans was detected in the artificial fissure only when the fissures were left in the mouth for a long period. This observation suggests either that the initial inoculation of the artificial fissures contained so few Strep. mutans that a long time was necessary for Strep. mutans to attain numbers sufficient for detection, or that Strep. mutans is a late arrival depending upon time and chance eventually to come in contact with the fissure. A third possibility is that certain conditions in the fissure brought about by other organisms eventually favours later colonization by Strep. mutans.

Our observations indicate that the salivary concentration of Strep. mutans, at which colonization of the artificial fissure occurs within the first few days. must be somewhere between $10^{2}-10^{4} \mathrm{CFU} / \mathrm{ml}$. After the salivary concentration of Strep. mutans had been reduced by oral hygiene, fluoride and dietary regimens to $10^{3} \mathrm{CFU} / \mathrm{ml}$ in subject $T$, the artificial fissures were not colonized by this organism at day 1. However, they were colonized by Strep. mutans at 2 and 5 days in 4 of 7 trials. This would place the colonization threshold somewhat below $10^{3} \mathrm{CFU} / \mathrm{ml}$ in these subjects. This value is lower than the salivary Strep. mutans level of $4.5 \times 10^{4} \mathrm{CFU} / \mathrm{ml}$ calculated

Table 6. Colonization of the AF by Strep. mutans and Strep. sanguis during the Strep. mutans reducing regimen (SMRR) in subject $S$

\begin{tabular}{|c|c|c|c|}
\hline $\mathrm{AF}$ in vivo & $\begin{array}{c}\text { Strep. mutans } \\
(\%)\end{array}$ & $\begin{array}{c}\text { Strep. sanguis } \\
(\%)\end{array}$ & $\begin{array}{l}\text { Total viable } \\
\text { count } \times 10^{7}\end{array}$ \\
\hline \multicolumn{4}{|c|}{ SMRR first 7 days in vivo } \\
\hline 14 days & 0 & 8.5 & 3.7 \\
\hline 35 & 0 & 6.9 & 0.9 \\
\hline \multicolumn{4}{|c|}{ SMRR last 14 or 21 days in vivo } \\
\hline 28 days & 9.6 & 13.5 & 3.3 \\
\hline 35 & 11.5 & 12.6 & 1.8 \\
\hline
\end{tabular}


by van Houte and Greene (1974) to be necessary for Strep. mutans to colonize a non-retentive smooth surface within 2 to $3 \mathrm{~h}$. That this value should be lower in the fissure is not surprising, as the fissure provides a stagnant space less accessible to the salivary flow dynamics and masticatory abrasive effects that occur on the smooth surfaces. Our findings suggest that fissures would be the first tooth surface areas colonized by Strep. mutans, which is in agreement with clinical data (Ikeda and Sandham, 1971).

The values of $10^{3} \mathrm{CFU} / \mathrm{ml}$ for colonization of the artificial fissure and $4.5 \times 10^{4} \mathrm{CFU} / \mathrm{ml}$ for colonization of smooth surfaces are based upon studies in which the saliva was homogenized by either a sonifier. as in our investigation, or a Vortex mixer (van Houte and Green. 1974). Such evenly dispersed salivary concentrations of Strep. mutans would not be found in vivo, where one would expect certain small volumes of saliva to be high in Strep. mutans and others to be low or devoid of this organism. Thus the Strep. mutans colonization threshold in saliva as determined by experimental data is an average and not an absolute value.

When Strep. mutans was found in the artificial fissures in subject $G$, the Strep. mutans to Strep. sanguis ratio in these fissures was less than 0.001 , reflecting a noncariogenic pattern (Loesche et al., 1975). This subject had the lowest salivary concentration of Strep. mutans and the lowest DMFS score. Conversely, in subject $S$, the Strep. mutans to Strep. sanguis ratio was below 0.01 at days 1,2 and 5 and then increased. so that by day 21 the value was 5.7 . This reflects a cariogenic pattern and this subject had the highest salivary concentration of Strep. mutans and the highest DMFS score. Subject $T$ had an intermediate Strep. mutans to Strep. sanguis ratio, an intermediate salivary Strep. mutans concentration and an intermediate DMFS score.

The increase in proportion of Strep. mutans with time in a fissure noted by us and by Thott et al., 1974 indicates that Strep. mutans possesses some advantage in the crowded confines of a fissure. The organisms in the initial inoculum may be the main, if not exclusive, determinants of the fissure flora at any time. If so, the eventual appearance of Strep. mutans in the fissure seen in subjects $G$ and $T$ after the Strep. mutans reducing regimen, would be the result of a small initial inoculum of Strep. mutans increasing with time to detectable levels, rather than a later colonization of the fissure by this organism. The studies performed on subject $S$. by varying the time sequence in which the Strep. mutans regimen was given and the artificial fissure was inserted, also support the suggestion that the initial inoculum determines the subsequent flora of the fissure. If the fissure was inserted during a period of SMRR. no colonization of the fissure by Strep. mutans occurred, even when the fissure was left in situ for additional 1 to 4 week period.

The failure of Strep. mutans to colonize the artificial fissure during the week of the SMRR could be attributed to the reduction of salivary Strep. mutans levels to values approaching the colonization threshold level of $10^{3} \mathrm{CFU} / \mathrm{ml} / \mathrm{min}$. (Fig. $1 \mathrm{a}$ and $\mathrm{c}$ ) and $/$ or to the accumulation of inhibitory levels of fluoride in the fissure and/or to the reduction of sucrose intake. If residual fluoride was present in the artificial fissure, it did not affect the total viable count and did not inhibit the Strep. sanguis colonization. However, a more specific effect on Strep. mutans adhesion is possible.

After the cessation of the SMRR the artificial fissures did not become colonized by Strep. mutans although the salivary concentration of this organism increased to values in excess of the colonization threshold. A probable explanation is that all the available space in the artificial fissures was already occupied by other microorganisms and no ecological niche was left for Strep. mutans. The experiments in which the artificial fissures were left in situ for two weeks prior to the introduction of the SMRR showed that the proportional increase in Strep. mutans was the same as in those experiments in which time was the only variable (Fig. 2). These data suggest that the microflora in the artificial fissure is a relatively closed system. Colonization by new organisms like Strep. mutans seems to be rare after the fissures have been occupied by a large number of organisms, i.e. within 1 day, and the confined environment favours the growth of some species such as Strep. mutans.

These observations suggest that antimicrobial efforts directed specifically against Strep. mutans about the time fissure surfaces enter the mouth may prevent this organism from colonizing these highly caries-susceptible surfaces. They also imply that antimicrobial therapy given after a fissure is colonized by Strep. mutans may have little if any effect on the fissure levels of Strep. mutans.

Acknowledgements-This investigation was supported by Public Health Service grants from the National Institute of Dental Research No. DE-03011, DE-02731 and DE-03423. Dr Thorkild Karring kindly provided us with several artificial fissures.

\section{REFERENCES}

Folke L. E. A., Sveen O. B. and Thott E. K. 1973. A method for study of plaque formation in natural human fiss'res. Scand $J$. dent. Res. 81, $411-414$.

van Houte J. and Green D. B. 1974. Relationship between the concentration of bacteria in saliva and the colonization of teeth in humans. Infect. Immun. 9, 624-630.

Gold O. G., Jordan H. V. and van Houte J. 1973. A selective medium for Streptococcus mutans. Archs oral Biol. 18, $1357-1364$.

Ikeda T. and Sandham, H. J. 1971. Prevalence of Strepto coccus mutans on various tooth surfaces in Negro children. Archs oral Biol. 16, 1237-1240.

Ikeda T., Sandham H. J. and Bradley E. L., Jr. 1973. Changes in Streptococcus mutans and lactobacilli in plaque in relation to the initiation of dental caries in Negro children. Archs oral Biol. 18, 556-566.

Löe H., Karring T. and Theilade E. 1973. An in vivo method for the study of the microbiology of occlusal fissures. Caries Res. 7, 120-129.

Loesche W. J., Rowan J., Straffon L. H. and Loos P. J. 1975. The association of Streptococcus mutans with human dental decay. Infect. Immun. 11, 1252-1260.

Loesche W. J. and Syed S. A. 1973. The predominant cultivable flora of carious plaque' and carious dentine. Caries Res. 7, 201-216. 
Syed S. A. and Loesche W. J. 1972. Survival of human dental plaque flora in various transport media. Appl. Microbiol. 24, 638-644.

Theilade E., Larson R. H. and Karring T. 1973. Microbial studies of plaque in artificial fissures implanted in human teeth. Caries Res. 7, 130-138.
Theilade E., Fejerskov O., Prachyabrued W. and Kilian M. 1974. Microbiologic study on developing plaque in human fissures. Scand. J. dent. Res. 82, 420-427.

Thott E. K., Folke L. E. A. and Sveen O. B. 1974. A microbiologic study of human fissure plaque. Scand. J. dent. Res. 82, 428-436. 